\title{
Theorizing About Socio-Technical Approaches to HCl
}

\author{
Abdelnour-Nocera, José; Clemmensen, Torkil
}

Document Version

Accepted author manuscript

Published in:

Human Work Interaction Design. Designing Engaging Automation

DOI:

10.1007/978-3-030-05297-3_17

Publication date:

2019

License

Unspecified

Citation for published version (APA):

Abdelnour-Nocera, J., \& Clemmensen, T. (2019). Theorizing About Socio-Technical Approaches to HCI. In B. R. Barricelli, V. Roto, T. Clemmensen, P. Campos, A. Lopes, F. Gonçalves, \& J. Abdelnour-Nocera (Eds.), Human Work Interaction Design. Designing Engaging Automation: Revised Selected Papers of the 5th IFIP WG 13.6 Working Conference. HWID 2018 (pp. 242-262). Springer. IFIP Advances in Information and Communication Technology Vol. 544 https://doi.org/10.1007/978-3-030-05297-3_17

Link to publication in CBS Research Portal

\section{General rights}

Copyright and moral rights for the publications made accessible in the public portal are retained by the authors and/or other copyright owners and it is a condition of accessing publications that users recognise and abide by the legal requirements associated with these rights.

\section{Take down policy}

If you believe that this document breaches copyright please contact us (research.lib@cbs.dk) providing details, and we will remove access to the work immediately and investigate your claim. 


\section{Theorizing About Socio-Technical Approaches to HCI José Abdelnour-Nocera and Torkil Clemmensen}

Article in proceedings (Accepted version*)

\section{Please cite this article as:}

Abdelnour-Nocera, J., \& Clemmensen, T. (2019). Theorizing About Socio-Technical Approaches to HCI. In B. R. Barricelli, V. Roto, T. Clemmensen, P. Campos, A. Lopes, F. Gonçalves, \& J. Abdelnour-Nocera (Eds. I, Human Work Interaction Design. Designing Engaging Automation: Revised Selected Papers of the 5th IFIP WV 13.6 Working Conference. HWID 2018(pp. 242-262). Springer. IFIP Advances in Information and Communication Technology, Vol.. 544 https://doi.org/10.1007/978-3-030-05297-3_17

This is a post-peer-review, pre-copyedit version of an article published in Human Work Interaction Design. Designing Engaging Automation: Revised Selected Papers of the 5th IFIP WG 13.6 Working Conference. HWID 2018. The final authenticated version is available online at:

DOl: https://doi.org/10.1007/978-3-030-05297-3_17

* This version of the article has been accepted for publication and undergone full peer review but has not been through the copyediting, typesetting, pagination and proofreading process, which may lead to differences between this version and the publisher's final version AKA Version of Record. 
Cite as:

Theorizing About Socio-Technical Approaches to $\mathrm{HCl}$

Abdelnour-Nocera, J. \& Clemmensen, T., 2019, Human Work Interaction Design. Designing Engaging Automation: Revised Selected Papers of the 5th IFIP WG 13.6 Working Conference. HWID 2018. Barricelli, B. R., Roto, V., Clemmensen, T., Campos, P., Lopes, A., Gonçalves, F. \& Abdelnour-Nocera, J. (eds.). Cham: Springer, p. 242-262 21 p. (IFIP Advances in Information and Communication Technology, Vol. 544).

\title{
Theorizing about Socio-Technical Approaches to HCI
}

\author{
José Abdelnour-Nocera ${ }^{1,2}$, Torkil Clemmensen ${ }^{3}$ \\ ${ }^{1}$ University of West London, School of Computing and Engineering \\ London, W5 5RF, England \\ ${ }^{2} \mathrm{M}-\mathrm{ITI}$, Funchal, Portugal \\ jose.abdelnour-nocera@uwl.ac.uk \\ ${ }^{3}$ Copenhagen Business School, Department of Digitalization, Frederiksberg, Denmark, \\ tc.digi@cbs.dk
}

\begin{abstract}
In this paper, we theorize about Socio-Technical approaches to HCI. The Socio-Technical tradition indicates that looking at design only or mainly from a technical design side is insufficient to design systems for work and workers; instead the social and the technical need to be co-designed and contingent on characteristics of the context, the organisation, and its historical development. However, it also argued that this tradition does not provide enough handles for the design of interactive technologies for users. We present Socio-Technical HCI as a distinct field of knowledge outlining the Socio-Technical traditions where it is rooted, and illustrate these with three different conceptual frameworks that have been used to support the design, development, and evaluation of interactive systems. These frameworks are Cognitive Work Analysis, Human-Work Interaction Design, and Technological Frames. These frameworks are compared and analysed in terms of what are a balanced and comprehensive way to in address socio-technical, contextual, and design issues in HCI. It is argued why HumanWork Interaction Design is best placed to address these issues.
\end{abstract}

Keywords: socio-technical, human-computer interaction, human work interaction design, cognitive work analysis, technological frames.

\section{Introduction}

The study of Human-Computer Interaction (HCI) has historically drawn on SocioTechnical (ST) traditions on attempt to provide an understanding of users' actions, which goes beyond cognitive and individual experience phenomena to incorporate the social, cultural and contextual character of interactive systems design, development,

adfa, p. 1, 2015.

(C) Springer-Verlag Berlin Heidelberg 2015 
evaluation and use. For instance, ethnographic methods with a sociotechnical perspective have been used in HCI to understand the work of end-users actions performed collaboratively with other people in a field setting. This implies that user activity is seen as a social and organisational experience. In this context, ST and HCI are interlinked in such a way to form a distinct field of knowledge, namely Socio-Technical HCI (STHCI). In this paper, we offer an overview of ST-HCI the ST traditions where it is rooted and illustrate these with three different conceptual frameworks that have been used to support the design, development and evaluation of interactive systems. These frameworks are Cognitive Work Analysis (CWA), Human-Work Interaction Design (HWID), and Technological Frames (TF). Compared to Activity Theory or Actor Network Theory, we believe the frameworks we have chosen offer practical ways to address contemporary design issues such as designing automation [1]from a ST-HCI HCI perspective. For example, HCI authors find that activity theory has some shortcomings when analysing dynamics over time [2]. Going beyond HCI, while actor network theory does explain how actors develop networks by translation and thus innovate technology [3] , how this is to be applied in HCI design is not clear. Other promising social theory for studying ST-HCI is Social Representation theory that explicitly addresses the temporal experience of meaning making [4] In social representation theory, work engagement should carefully be anchored in, e.g., stabilised into, an existing HCI design goal such as user experience, and then objectified through a series of research studies and practical design projects that would gradually lead to established HCI design goals. However, HWID, CW and TF have the advantage, compared to the above theories, that they are already narrowly focused on interaction design and well-known HCI methods for empirical socio-technical analysis.

The paper first provides an overview of ST traditions and then presents series of key questions ST-HCI should be able to answer. This is followed by a presentation of instances of ST-HCI in the form of brief case studies featuring CWA, HWID and TF. These case studies are then discussed in terms of the key questions introduced earlier. From this we go onto a discussion of what each perspective provides to ST-HCI and the distinct characteristics of this field of knowledge. Based on this discussion, the paper concludes with recommendations about the most suitable ST-HCI approach.

\section{Socio-technical Traditions}

ST traditions and approaches stem from two different scientific traditions: one that emerged from organisational studies conducted by the Tavistock Institute of Human Relations in London in the late 40s and 50, [e.g. 5, 6], and one that emerged from a group of authors concerned with the social shaping of technology [e.g. 7, 8]. SocioTechnical systems theory key principles were originally proposed by Trist and Bamforth [6] and are aimed at increasing both productivity and worker satisfaction through joint optimisation of the social and technical components of organisations. These principles recognise the need to empower workers in decision making and focus on whole tasks as main units of analysis beyond any spatial-temporal boundaries. The main tenet 
of Socio-Technical systems theory is that introduction of technology innovation without the consideration of organisation's existing structures and division of labour can lead to a decrease in productivity and worker satisfaction. Job enrichment, as opposed to job enlargement, is claimed as the immediate benefit for workers. These principles were later developed by Mumford [9] through her ETHICS methodology for the design of information systems, where the participation of workers, as users, in decision making is a basic condition for satisfaction and usefulness. Unfortunately, despite ST approaches emphasis on user involvement and decision making in organisational work contexts, no clear handles have been provided by authors like Mumford [9] and Cherns [5] to interactive system designers trying to make their systems not only more usable, but also more useful and satisfying from a user experience perspective. Dillon [10] defines this gap very well by pointing out that 'Criteria for effectiveness, efficiency and satisfaction must be derived from the social not the individual context of use' and calls for ST approaches to be operationalised at the level where user interactions are designed.

Authors in the Sociology of Technology are ontologically concerned with SocioTechnical phenomena $[7,8,11,12]$. They converge on the fact that the character of technology is situated, interpretatively flexible and socially shaped and shaping. They usually produce concepts and theories aimed at making sense of Socio-Technical change and diffusion. For instance, the concept of technological frames by Bijker [13], tries to capture the interpretive frames and social dynamics that influence the social construction of technology. Actor network theory (ANT) proposed by Latour , [14], presents an approach to understanding Socio-Technical phenomena through the agency of networks of human and non-human actors. A key concept in ANT is that of translation [3], as it explains to understand how technology innovation is the consequence of the successful re-alignment of actors willing to sustain and develop the corresponding network. In ANT networks are inherently Socio-Technical since human and non-human actors can have mediating roles depending on their situation in the network. Technological frames and ANT are good examples of how theories can be used to make sense of technology design and use.

The key difference between the two ST traditions discussed above is an epistemological one which can be summarized into a constructive-critical dimension: knowledge in ST systems theory is aimed at problem resolution in the design of work systems (constructive), while knowledge in the Sociology of Technology is aimed at a rich understanding of Socio-Technical change (critical). ST-HCI inherits from Socio-Technical this epistemological double aim of design and understanding but adapting it to HCI. 


\section{Questions to ask Socio-Technical traditions from an HCI Perspective}

There are questions to ask to the ST traditions from an HCI perspective. The key characteristic of almost all ST research variants, even those close to systems thinking traditions or to Marxist inspired system development approaches, is that ST challenges a purely technical perspective.

Here HCI may 1) ask exactly which interpretation of all the variants of ST is useful for HCI research and practice, which has indeed a specific technical perspective on the interactions with computers. While the starting point is typically some (new) technology, ST research does not focus on technology per se, but on social issues on four different levels: the interaction level (HCI, UX, Interface), the individual level (job satisfaction, job design, automation), the organizational level (decentralization, decision making, business models, strategy) and/or societal level (unemployment, privacy, wealth distribution) [15].

So, HCI may ask, 2) how can HCI researchers take into account several levels of the social while still focusing on the interaction design? Though some variants of ST may offer more practical guidance as to "how to develop systems, how to manage implementation or how to identify exciting IT inventions/innovations”, other ST variants, despite being offered prominent positions such as CHI keynotes have not yet been shown to support the actual design of HCI.

So thirdly, HCI may ask 3) how to conceptualize the computer/interaction and give recommendations for design? Obviously, design is highly contextual, "design becomes a set of routines that emerge in context” [16]. ST has to some degree acknowledged the importance of context, e.g., by modifying US based textbooks on Management of IT to match the local context [15].

However, HCI may ask 4) how should context be taken into account? A forceful argument is that changes in economic paradigms enforce new contexts for HCI: from the usability of industrial economy, the user experience of the experience economy, the social media and open platforms of the knowledge economy, and most recently, the ethical issues and emphatic livings labs of the transformation economy [17]

In the next section we demonstrate how ST-HCI approaches sitting in different epistemologies should help answering these four questions.

\section{Epistemologies that allow us to explore Socio-technical HCI Perspectives}

Our aim with ST-HCI is to articulate epistemologies that provide researchers with a flexible standpoint in their approach to HCI design. According to Guba [18], theorising from a relativist ontology and epistemology, as in in the case of ST-HCI, recognises that the production of theories will never be exhaustive or absolute, and that knowledge is possible only through interaction of the inquirer and the inquired. ST-HCI researchers recognise the need for these interactions and see knowledge as a continuous coconstruction, where researchers, developers, designers, managers and users can be the 
subjects and objects of inquiry. ST-HCI epistemological positions fundamentally serve two different types of purposes.

On one hand ST-HCI can enable an understanding of ST change, - drawing on theories in the Sociology of Technology such as Actor Network Theory or Technological Frames, which is discussed later in this paper. ST-HCI can facilitate the integration of concepts and perspectives that enable the identification of scripts and power relations inscribed in work systems, and, by implication, with the interpretive and experiential dimensions of workers' engagement. While this knowledge is not directly instrumental to support design decisions, it is a legitimate way to make sense of ST change in the context of the workplace as a complex network of human and non-human actors.

On the other hand, ST-HCI can also help to solve ST design practical problems - in the spirit of the Tavistock tradition. This means that visualising relations between the work domain, interaction design and work systems can lead to an iterative set of contingent tools and rules with explicit implications for design decisions for workers' utility, usability and user experience goals. In this case, the knowledge produced is not aimed at understanding the social and political nuances shaping ST change as an organic process but aimed at solving practical interaction design problems in the context of ST systems. In the following sections we present 3 different instances of ST-HCI conceptual frameworks.

\subsection{Cognitive Work Analysis}

ST traditions share a general concern: provide knowledge that can be used to create systems that 'fit' with users and their context. However, while interaction design offers handles to support design decisions for user interfaces, methods in work analysis provide structural and/or contextual models of actors and information flows, not necessarily concerned with interface design. As a response to these limitations in work analysis, Vicente [19] developed CWA as a framework to model complex Socio-Technical work systems. Within this framework, Ecological Interface Design (EID) emerges as set of analysis methods to support decision making in the processing and presentation of information according to end-users and their role as actors in the work system. CWA and EID fall clearly within a functionalist paradigm as per Hirschheim's paradigm of information systems development [20].

We illustrate the use of CWA in a case study used to support design considerations for the Smart University system [21]. This technique is driven by a framework that supports and structures the analysis needed when designing a flexible and adaptive system. The framework focuses on analysing the limitations and constraints on workers behaviour; and mapping these constraints is the design of the system that will support the workers.

The CWA framework comprises five different phases; work domain analysis, control task (or activity) analysis, strategies analysis, social organisation and co-operation analysis, and worker competencies analysis. Using CWA has two distinct advantages. First, CWA is a multi-dimensional analysis that incorporates the physical and the social environment to provide a rich description. Secondly, CWA can be paired with Ecological Interface Design (EID) [22] to generate designs for new information systems. EID 
has shown success in the design of analytic information displays in power plant displays [23]; social systems [24], healthcare decision support [25] and community building [26]. For these reasons, CWA is a viable approach in cyber physical systems such as those supporting smart work environments. We now illustrate CWA briefly with a scenario focused on smart universities:

A lecturer, who offers weekly online exercises has the intention to help his/her students to prepare for an exam. But she is not sure if the currently available exercises are helpful enough for this purpose. Therefore, he/she would like to know if those students who practice with her online exercises on a weekly basis are better in the final exam than students who do not use them. A Learning Analytics toolkit could help him/her to do research on this hypothesis by automatically collecting, analyzing, and visualizing the right data in an appropriate way. The smart university platform should allow for interactive configuration in such a way that its users could easily analyze and interpret available data based on individual interests. We present this scenario through the lens of the different phases of CWA.

Work Domain Analysis (WDA) provides an overview model of the work environment with a view to understanding what kinds of information should be included in the user interface and how this should be presented. The learning analytics toolkit is part of a ST system whose main goal is maximising learning outcomes and the learning experience for students. Table 1 presents an Abstraction Hierarchy (AH) typically used for WDA [25]. This is made of five levels, which are now described in terms of the learning analytics scenario:

Table 1. Work domain analysis for learning analytics scenario

\begin{tabular}{|l|l|}
\hline \multicolumn{2}{|c|}{ WDA: supporting exam preparation } \\
\hline $\begin{array}{l}\text { Physical } \\
\text { form }\end{array}$ & $\begin{array}{l}\text { for student (type, program, year of admission, status, performance level); for } \\
\text { learning material (type, date available); for evaluation material (type, date of } \\
\text { evaluation, grades achieved), for lecturer (level, name, availability); for student } \\
\text { record system (type, data available, dates accessed) }\end{array}$ \\
\hline $\begin{array}{l}\text { Physical } \\
\text { function }\end{array}$ & $\begin{array}{l}\text { Student, VLE, Lecturer, university student record system, material to be } \\
\text { learned, evaluation material }\end{array}$ \\
\hline $\begin{array}{l}\text { General- } \\
\text { ized } \\
\text { function }\end{array}$ & $\begin{array}{l}\text { Student accessing material, lecturer creating and uploading new material, con- } \\
\text { tributing to discussion board, monitoring and evaluation of student's progress }\end{array}$ \\
\hline
\end{tabular}




\begin{tabular}{|l|l|}
\hline $\begin{array}{l}\text { Abstract } \\
\text { function }\end{array}$ & Balance the ratio of evaluation to learning \\
\hline $\begin{array}{l}\text { Func- } \\
\text { tional } \\
\text { Purpose }\end{array}$ & Maximize learning outcomes, Maximize student experience \\
\hline
\end{tabular}

Since education is a core goal of this scenario, learning needs to be present in the functional purpose and generalized function levels. The scenario indicates that there is a concern that weekly exercises might improve learning, as evaluated through exam results, or might not be helpful. This is why we have chosen to describe at the abstract function level that there must be a balance between evaluation and learning, e.g. you cannot evaluate $100 \%$ of the time, but you also need to evaluate at some level. The functional purpose is to find the sweet spot where learning outcomes and student experience are maximised at optimum levels.

WDA will allow us to identify the analytics data needed for designing components of the system. For instance, a key goal derived from this WDA is to enable the instructor to move that sweet spot between evaluation and learning to maximize outcomes and experience. Those are the drivers, i.e. decisions to be made with the analytic system.

Control Task Analysis is done to determine what tasks are being carried within the system and under what conditions. In this learning analytics scenario, control task analysis (ConTA), based Rasmussen's decision ladder [26], the analysis would look like in Figure 1. Is there uncertainty and ambiguity on the possible goal state? Quite possibly, if the instructor is following a new evaluation approach for students, she may move into knowledge-based behavior trying to figure out what is wrong. Analytics could play a role here. Instructors can then 'define a task', i.e. choose to modify their instruction approach. This implies setting a new 'procedure', more or less exercises in this case, which would then be 'executed'.

Strategies, Social and Worker Competencies are also critical. This level of analysis can facilitate the discussion of different teaching strategies (traditional, flipped, blended learning). This could also reveal different evaluation strategies (short quick frequent evaluations, longer midterm/final, or project based evaluation).

The identification and description of social competencies could represent values and intentional constraints being conveyed by the institution. It could also consider the culture and cooperation of the students in this. As a worker, the instructor must have competency in teaching, the material being taught, and the use of the smart learning system. Skills, rules and knowledge is the base for all of these. 


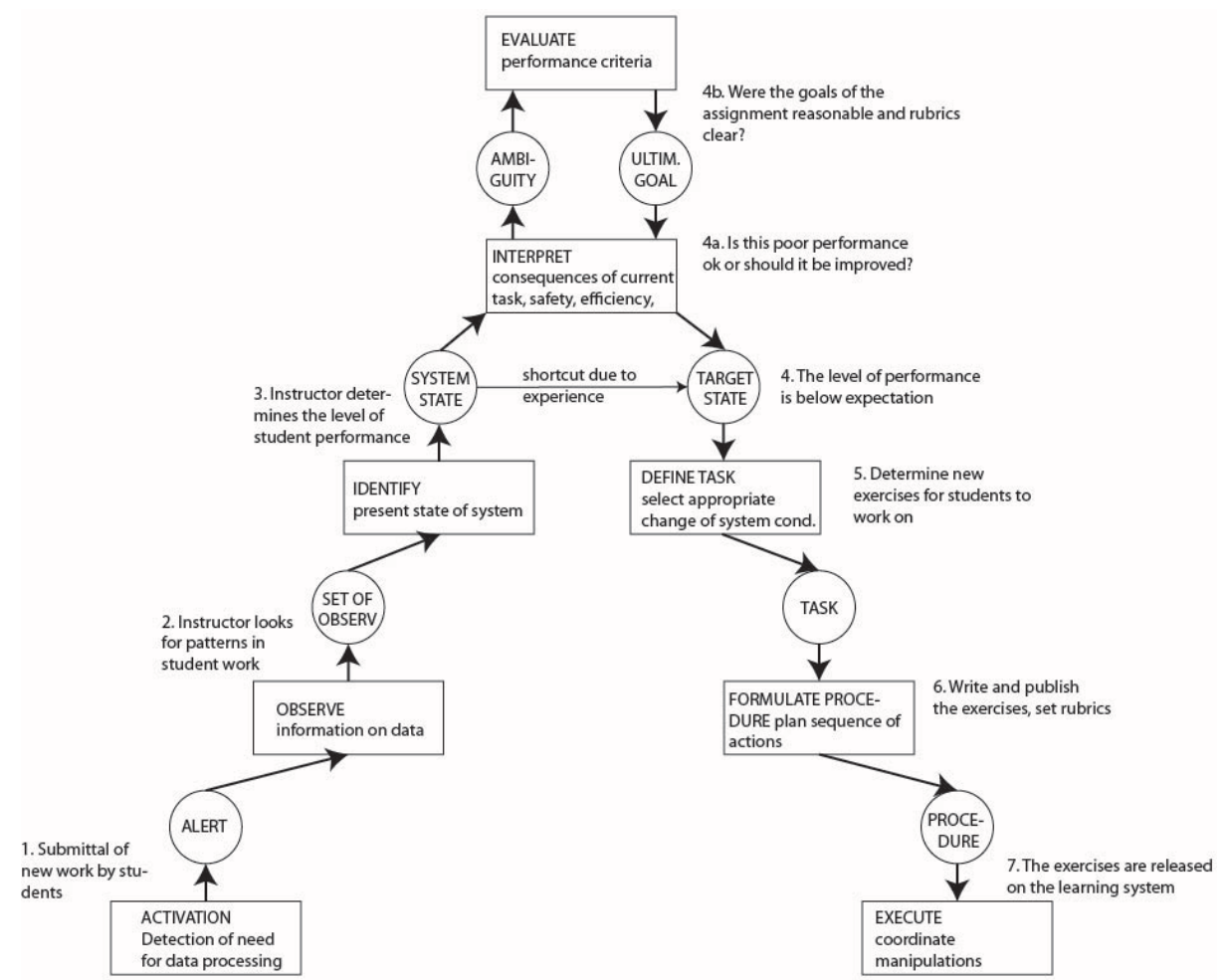

Fig. 1. Decision ladder for learning analytics scenario.

Looking at this scenario through the CWA approach supports the HCI decisions on which usability and user experience goals that should drive the interaction design of the different interface components of the smart university sociotechnical system. The CWA of the learning analytics scenario clearly points to importance of effectiveness and utility [27] as main usability goals driving the design of the user interface of the lecturer trying to establish the optimum level of exercises that should be set for students to meet learning goals in a satisfactory way.

In terms of design guidelines feedback and mapping become core objectives in the presentation of the student performance data. Good user interface design meeting these goals and principles will support the overall functional purpose of the learning analytics systems, i.e. Maximize learning outcomes, Maximize student experience.

\subsection{Human Work Interaction Design}

The problem with CWA and its derivative method, EID, is that they are framed with a mainly functional paradigmatic view of information systems and this limits a more rel- 
ativistic approach to study of user engagement in the context of work systems. However, sharing with CWA theoretical roots in cognitive engineering research at Risø National laboratory in Denmark [28], an alternative approach called Human Work Interaction Design emerged around 2005 [29]. HWID as a framework is sitting in a socialrelativistic paradigm [20], and can thus contribute to the design of systems supporting work satisfaction and positive organisational ST HCI design goals. Below we outline the current version on the HWID framework, see also figure 2.

HWID studies how to understand, conceptualize, and design for the complex and emergent contexts in which information and communication technologies (ICT) and work are entangled. Several aspects influence the way humans work and the work itself. For humans, language, culture, education, skills, knowledge, emotions and cognitive abilities contribute to define the profile of users and their approach to individual and collaborative work. For work, its goals, functions, available tools and content contribute to delineate its characteristics and challenges.



Figure 2. The HWID framework by Clemmensen [30]

The HWID leans heavily on the HCI and human factors traditions specific interpretation of the social and the technical elements of the ST system. In contrast, the social in ST has been described as a broad 'concern with the human workers job satisfaction 
in a broad sense', and the technical in ST has been described as in general 'the IT system' $[6,15]$.

In contrast to ST's general concern with the human workers' job satisfaction in a broad sense, in HWID the social is analysed as end-users' work tasks performed through IT systems within a given work domain. The focus is on the user's experience of tasks (procedures) and the IT artefact environmental constraints as a work domain. Hierarchical Task Analysis [31] and Work Domain Analysis [32] are among the methods that can be used to analyse the goal-directed tasks, and map the work environmental constraints and opportunities for behaviour. In addition, there is a strong tradition in HCI for studying work with ethnographic methods [33] and from Socio-Technical perspectives, e.g.,[34]. These approaches focus on work as end-user actions performed together with other people in a field setting, that is, the user's experience of using systems are social and organizational experiences. User experience, usability and interaction design are influenced by these approaches and techniques for analysing and interpreting the human work, which eventually manifests in the design of technological products, systems and applications.

In contrast to ST's general focus on 'the IT system', the technical in HWID focus either on interaction designs as such, i.e., user interfaces, or focus at interaction design methods and techniques, i.e., think aloud usability evaluation, sketches, prototypes, and more. Interaction design is presented in textbooks as an approach consisting of conceptual models, scenarios, task analysis, persona, think-aloud evaluation, and other usercentred techniques $[27,35]$. In addition to being user-oriented, textbook approaches to interaction design also focus on the use of prototypes, storyboards and sketches, which interaction designers see as products or sources of inspiration in the design process rather than the interaction design itself. For example, sketches, such as freehand drawings or low-fidelity prototypes, have been studied for their role in design and have been found to stimulate reflection, particularly in the early stages of design [36]. When moving from analysis to design, that is, from conceptual models to physical design, interaction design relies heavily on iterative usability and UX testing of prototypes with users of the future product. A large number of techniques for user requirement elicitation and user tests are available for use in interaction design [27]. In many of these techniques, communication between stakeholders about user requirements is supported by the use of prototypes, mock-ups, and sketches.

We now present an example articulating HWID as a form of ST-HCI. Barricelli et al. report from a long terms case study of an interdisciplinary collaboration between several domain experts in the frame of archaeological projects. Since 2001, different independent interactive systems have been co-designed, developed, and tested on the field, in the frame of the "Tarquinia Project" carried out since 1982 in the ancient Tarchna, one of the foremost Etruscan cities, by the Università degli Studi di Milano. This project concerns the involvement of domain experts, the main characteristics and challenges of the archaeological practice, and how to design and apply technology to support the work and user experience of archaeologists as they engage with their tools and tasks.

Barricelli et al. [37] apply a semiotic approach to the archaeological domain and put in practice a participatory action design research method. Barricelli et al. [37] argue 
that the archaeological application domain is characterized by strong social and organizational factors, and thus a framework like HWID is needed to ensure a successful theory-based introduction of technology and interactive systems. They argue that the framework does not force a technology/design perspective on the case but allows the interaction of work and the ID to evolve. They applied their favourite theoretical and methodological tools and adapt these to the case, all within the overall framework which provided a holistic gestalt for a set of very diverse approaches, ranging from User Centered Design (UCD) to technical design.

They followed five stages: 1 ) analysis of the domain with open problems identifications ; 2) detection of opportunities and open challenges to be addressed with a participatory approach ; 3) actual design with the use of prototypes and recurrent usability evaluations; 4) measurement of impact evaluation with the active involvement of the members of the interdisciplinary team on the field; 5) generalization of the outcomes in a model that reflects the expertise that the researchers developed in the domain.

The case study documents the interactions between the 'human work' and 'interaction design' streams in the HWID framework. For the 'human work' stream, typical archaeologist methods and tools are referenced: non-intrusive (e.g., analysis of aerial photography for landscape alterations, use of ground-penetrating radar to find buried anomalies, and the systematic, controlled collection of materials from surface contexts) and intrusive (e.g., shovel testing, test units, and excavation blocks, each with different range). Archaeologists analyse and interpret these remains in relation to how and why cultures evolved over time. For the 'interaction design' stream several methods and tools are referenced: technological approaches, e.g., mobile or web applications, supporting data collection on site, 3D modelling, processing, and visualization technology support modelling, e.g. create replicas of how the soil layer looked and the position of artefacts and structures. The case study highlights the crucial value of the user experience of archaeologists in interacting with data platforms ensuring a correct management of the cultural objects contained in the original sources.

The HWID framework may help formulate findings in relation to how environment and context: strongly influenced the archaeological practice, e.g., the distributed nature of the work (on excavation site, in storage rooms, in laboratories, in universities), the interdisciplinary work with the involvement of experts from different domains, and the international collaborations that highlighted the existence of experts' sometimes radically different methods, use of different languages (not only in terms of spoken language but also visual notations) and remote interaction (most of the time asynchronous and written).

The overall objective of the research reported in this case study is how to facilitate and perform the co-design of a cloud of services aimed at integrating all the tools into a bigger framework to support the work practice and user experience of archaeologists in a more pervasive and engaging way. What is learned from this case study is that all four main elements of the HWID framework: theory, context, work, interaction design, are all related to the overall goal of work engagement as both a process and an outcome of design: involving and supporting domain experts in the design of their own practice and tools. While HWID is clearly in Social Relativistic epistemology as per Hirschheim's taxonomy [20], ST-HCI can also engage with more radical structuralist stances. 
The next section presents an example drawing on concepts from the sociology of technology.

\subsection{Technological Frames}

This section presents a framework based on the concept of Technological Frames (TF) $[13,34,38]$, which enables the identification and understanding of the symbolic, material and political dynamics that shape the co-configuration of people, culture and technology in social groups. A TF is constituted by people's interpretive frames and practices that lead to the attribution of meaning to technology. TF give a sociotechnical account of the social shaping of technology and the technology shaping of society and, it is argued, of the process of technical and knowledge communication that go with these processes.

The concept that an important gap exists between producers and users, which can make information systems irrelevant for their intended users is well established and is congruent with Suchman's work [39] . TF provide a means of explicating and analyzing the situation so that interpretive frames and practices of the different stakeholders in a system can be understood and modified or mitigated. Moreover, it is recognized how these frames and practices are subject to political and power relations.

TF analysis is underpinned by the assumption that the usefulness of technology is shaped by the socio-cultural conditions of its stakeholders. This idea is a core element of the Social Construction of Technology approach (SCOT) [7] and is central to the research reported here. SCOT focuses on how diverse meanings are attributed to technology and the interpretive flexibility of technology. In this context, technology is not only defined in the sense of tangible artifacts, but also in terms of knowledge and methods, which makes the TF perspective relevant to the field of technical and knowledge communication.

Usually, the different elements of TF are identified by analysing qualitative data in the form of field notes, documents, observation logs and interviews. However, the creation of categories of analysis can also be based on assumptions and previous experience with the groups studied. The example analysis provided here is based on data gathered in the first visit of the VESEL project team to Kenya as well as some assumptions from the researchers based on their experience of introducing technology in similar contexts. The VESEL project (Village E-Science for Life) brought together British and Kenyan universities to define the most urgent information requirements for a rural farming community and to design the appropriate technologies to meet these needs. The TF elicited from these data are not static and change over the development lifecycle. This is done by an iterative cycle of production and evaluation of sociotechnical scenarios by the producers and, ideally, users of the technology - for more information on this process see Hansen [40].

In order to study TF elements, Bijker [13] would identify the goals and problems that a particular social group had with respect to a particular technology. Table 1 summarizes goals and problems of producers and users with respect to the technology designed in the VESEL project [41]. The table presented here is not a full-blown analysis but a proof-of-concept exercise to illustrate the value of TF. Elements from the TF of 
the members of the VESEL team (producers) are compared with those of the farming communities (users).

Table 2. An illustration: Technological Frames in the VESEL project.

\begin{tabular}{|c|c|}
\hline \multicolumn{2}{|c|}{ Technological Frames in VESEL } \\
\hline Producers & Users \\
\hline \multicolumn{2}{|r|}{ Goal } \\
\hline $\begin{array}{l}\text { Create effective ICT systems using sen- } \\
\text { sor networks to improve quality of life of ru- } \\
\text { ral farming communities. Enabling access to } \\
\text { new markets. }\end{array}$ & $\begin{array}{l}\text { Improve the quality of their farming knowledge } \\
\text { and market network. Improve their productivity } \\
\text { and profitability with the least effort }\end{array}$ \\
\hline \multicolumn{2}{|c|}{ Problems } \\
\hline $\begin{array}{l}\text { Keep to fund holders budget in terms of } \\
\text { cost, time scale and resources. } \\
\text { Need to be innovative. }\end{array}$ & Having suitable ICT tools to support their work. \\
\hline \multicolumn{2}{|c|}{ Elements of Interpretation } \\
\hline $\begin{array}{l}\text { Universality of Technology } \\
\text { Technical Centredness }\end{array}$ & $\begin{array}{c}\text { History of village, perception of socio-political } \\
\text { boundaries, established expectations of tools and } \\
\text { technology, perception of foreigners. } \\
\text { No or little previous experience with Technology } \\
\text { Rumours of other groups with access to PC. }\end{array}$ \\
\hline User awareness in terms of expectations & \\
\hline \multicolumn{2}{|c|}{ Elements of Practice } \\
\hline $\begin{array}{l}\text { Development practices which are incon- } \\
\text { gruent } \\
\text { Limited contact with Users }\end{array}$ & $\begin{array}{l}\text { Local Working Practices: interaction protocols for } \\
\text { knowledge transfer among villagers, tool media- } \\
\text { tion. } \\
\text { Subscription to Technology vs. workarounds: sub- } \\
\text { stitution vs. accommodation/ integration? } \\
\text { Problem Locus Construction: what is wrong } \\
\text { with what we do? Why do we need these tools? }\end{array}$ \\
\hline
\end{tabular}


The table shows that the Elements of Interpretation and Practice between producers and users are different. This is not surprising as they come from different technological and cultural backgrounds. Producers had to constantly review their assumptions about the universal usefulness and validity of technical artefacts and locate them in the context of these communities. Initial meetings in the VESEL team highlighted the technical centred perspective of some developers, which did not question the situated usefulness and relevance of the scientific content and functions being implemented in the system. The application of TF facilitated the reflective analysis of the language and discursive and political practices surrounding technology of all the groups involved in VESEL, which had a direct impact on the design of metaphors in the user interfaces of the systems being designed - for further description of this impact see [42].

\subsection{Summary}

In summary, in table 3 we revisit the questions that we posed in section 3.

Table 3. Differences between CWA, HWID, TF

\begin{tabular}{|c|c|c|c|c|}
\hline & & CWA & HWID & TF \\
\hline & $\begin{array}{l}\text { Exactly which inter- } \\
\text { pretation of all the } \\
\text { variants of ST is use- } \\
\text { ful for HCI research } \\
\text { and practice? }\end{array}$ & $\begin{array}{l}\text { CWA including EID } \\
\text { has proven useful to } \\
\text { expert work analy- } \\
\text { sists ( Vicente 1999r) } \\
\text { to help dig deep into } \\
\text { a work domain }\end{array}$ & $\begin{array}{l}\text { HWID has proven } \\
\text { useful for enabling di- } \\
\text { alogues between work } \\
\text { analysis and interac- } \\
\text { tion designers across } \\
\text { various contexts }\end{array}$ & $\begin{array}{l}\text { TF has proven useful to } \\
\text { focus on the social con- } \\
\text { struction of technology } \\
\text { within organizations }\end{array}$ \\
\hline 2. & $\begin{array}{l}\text { How can HCI re- } \\
\text { searchers take into } \\
\text { account several levels } \\
\text { of the social while } \\
\text { still focusing on the } \\
\text { interaction design? }\end{array}$ & $\begin{array}{l}\text { One of the five pro- } \\
\text { posed phases of } \\
\text { CWA - work domain } \\
\text { analysis (WDA) - } \\
\text { offers a five level } \\
\text { analysis of the work } \\
\text { domain that feed into } \\
\text { later stages of eco- } \\
\text { logical interaction } \\
\text { design }\end{array}$ & $\begin{array}{l}\text { Interaction design } \\
\text { (ID) on the individual } \\
\text { user/employee level is } \\
\text { seen as mutually } \\
\text { shaping organiza- } \\
\text { tional and work (HW) } \\
\text { analysis level issues } \\
\text { in a process that also } \\
\text { take into account the } \\
\text { wider context }\end{array}$ & $\begin{array}{l}\text { Interpretive technolog- } \\
\text { ical frames (TF) and } \\
\text { practices of the differ- } \\
\text { ent stakeholders in a } \\
\text { system - rather than so- } \\
\text { cial levels - are under- } \\
\text { stood and modified or } \\
\text { mitigated }\end{array}$ \\
\hline 3. & $\begin{array}{l}\text { How to conceptualize } \\
\text { the computer/interac- } \\
\text { tion and give recom- } \\
\text { mendations for de- } \\
\text { sign? }\end{array}$ & $\begin{array}{l}\text { The WDA analysis } \\
\text { within CWA helps } \\
\text { identify major usa- } \\
\text { bility and UX goals } \\
\text { for design based on } \\
\text { the work domain and } \\
\text { work tasks }\end{array}$ & $\begin{array}{l}\text { Relations between } \\
\text { work (HW) and inter- } \\
\text { action design (ID) } \\
\text { happens through and } \\
\text { is expressed in design } \\
\text { artefacts }\end{array}$ & $\begin{array}{l}\text { TF's interpretive flexi- } \\
\text { bility of HCI designs } \\
\text { lead to recommenda- } \\
\text { tions about tangible ar- } \\
\text { tifacts and knowledge } \\
\text { and methods for tech- } \\
\text { nical and knowledge } \\
\text { communication }\end{array}$ \\
\hline 4. & $\begin{array}{l}\text { How should context } \\
\text { be taken into ac- } \\
\text { count? }\end{array}$ & $\begin{array}{l}\text { Context is under- } \\
\text { stood and modelled } \\
\text { in CWA at different } \\
\text { levels, including } \\
\text { physical description } \\
\text { of a work domain }\end{array}$ & $\begin{array}{l}\text { What is the relevant } \\
\text { HWID context is de- } \\
\text { termined by the tem- } \\
\text { poral unfolding of re- } \\
\text { lations between indi- } \\
\text { vidual interaction de- } \\
\text { signs and organiza- } \\
\text { tional work issues and } \\
\text { processes }\end{array}$ & $\begin{array}{l}\text { The context for TF is } \\
\text { always an organiza- } \\
\text { tional context, and not } \\
\text { the wider societal or } \\
\text { technological context }\end{array}$ \\
\hline
\end{tabular}




\section{Discussion}

HCI like ST challenges a purely technical perspective on computer design and use. The three ST-HCI frameworks that we have presented in this paper all take into account the social aspects and at the same time conceptualize technology. They all offer a way to theorise about HCI in ways pointed Clemmensen et al. [2]: on one hand we are the first level of meta-theoreticians where we are comparing different socio-technical theoretical traditions and analyze its features, principles and problematic aspects; by focusing on concrete conceptual frameworks within each of them, we are also at the second level where we assess and extend CWA, TF and HWID as an analytical tools to support the design of socio-technically aware interactive systems. They are all candidates for a socio-technical foundation for HCI that goes beyond cognitive and individual experience phenomena to incorporate the social, cultural and other contextual character of interactive systems design, development, evaluation and use. Much needed in the global HCI world of today. However, the three approaches are also different, and perhaps not equally suited for empowering the individual human in her interaction with computers within the wider context. In table 3 and the following sections, we revisit the questions from section 3 and use these to discuss the differences between the three frameworks, and which one to choose for HCI.

\subsection{Differences between CWA, HWID, TF}

Which interpretation of the variants of ST is useful for HCI research and practice? HCI may ask exactly how each of the three frameworks are most useful to HCI research and practice and its traditional individualistic and technology deterministic view. While HCI traditionally focus on individual human-computer interaction and takes point of departure typically in some (new) technology, ST research does not focus on technology per se, but on social issues on different levels.

CWA including EID has proven useful to expert work analysists [43] to help dig deep into 'causal' or physical work domains, in contrast to 'intentional' work domains such as office work [24]. The analysis of control tasks and the work domain are but two of the methods that look at the wider social, physical and technological contexts of human technology use [44] Thus the positivist and functionalist epistemology of CWA is useful for HCI design in certain domains, mostly safety critical and complex work domains.

HWID has proven useful for enabling dialogues between work analysis and interaction designers across various contexts [45]. The relational epistemology of HWID and its explicit focus on the relations between interaction design and work analysis has enabled a dialogue about how to design for the individual within the wider contexts, i.e., how to keep the tradition of the psychology of HCI but embed the notion of usability into a globalized dialogue [46]. Hence HWID is useful for moving HCI incrementally towards a wider and more diverse understanding of the psychology of the user in digitalized work environments.

TF has proven useful to focus on the social construction of technology within organizations [34]. Usability is thus within TF constructed as a stakeholder perspective, e.g., 
librarians may themselves acts as usability experts evaluating digital library systems [47]. TF's view of usability and other HCI issues as socially constructed is clearly different from CWA's view of HCI issues as phenomena occurring in physical environments; in contrast HWID's view of HCI issues as relational issues does not take a strong position on the nature of $\mathrm{HCI}$ issues.

How can HCI researchers take into account several levels of the social while still focusing on the interaction design? Given that ST traditionally deals with several levels of human-technology interaction, of which HCI is only one: the interaction level (HCI, UX, Interface), how will the different frameworks for ST-HCI take into account also the other levels: the individual employee level (job satisfaction, job design, automation), the organizational level (decentralization, decision making, business models, strategy) and/or societal level (unemployment, privacy, wealth distribution)? How can HCI researchers take into account several levels of the social while still focusing on the interaction design?

In CWA, one of the five proposed phases is work domain analysis (WDA). It offers a context-independent five-level analysis of the work domain, see Table 1, which feed into later stages of ecological interaction design. Later development of CWA has led to new social dimensions of CWA such as 'team dimensions'[44]. The objective of Team WDA is to understand how work domain constraints influence a team on different levels. For example, team members may have shared objects or processes, team members may have objects or processes that are not shared, team members may have shared purposes, or team members may have different or conflicting purposes. However, CWA tends to model 'levels of physical reality' rather than 'levels of an organization' or levels of other social entities.

In HWID, Interaction design (ID) on the individual user/employee level is seen as mutually shaping organizational and work (HW) analysis level issues in a process that also take into account the wider context. The relational epistemology of HWID indicates that what is the appropriate level of HCI analysis and how to understand what is an HCI evaluation technique will change depending on the current relation between interaction design and work analysis and the current wider contexts. For example, 'contextual personas' in HWID are focused not on the usage of one system but on describing the whole context of work [48]. Thus a contextual persona could typically be using 20 software systems for solving various tasks at work. Thus in HWID personas are used not as positivist depictions of real target user groups, but as a reflexive tool to be used as trigger material when talking with users, which for example could be the diverse and multifaceted work of the business administrators, see [48].

In TF, the interpretive frames and practices of the different stakeholders in a system - rather than social levels - are understood and modified or mitigated. The constructivist-critical approach of TF emphasizes the social and political rather than the technical. For example, when different groups of users with differing HCI experience evaluate usability a TF analysis will reveal how the evaluation reports are shaped by the different technological frames of the evaluators, and how and at what stage these frames were translated between different groups [47]. In VESEL, it could be seen how farmers and researchers had different political agendas on the development of the technology to be 
deployed as depicted in their TFs [41]. TF thus tends to model, rather than the technical, mostly the social, organizational and political levels.

While CWA tends to model 'levels of physical reality' rather than 'levels of an organization', TF in contrast focus on the social, political and organizational levels. HWID takes a flexible approach and take into account various social and technical levels depending on what relations between work analysis and interaction design that is currently in focus.

How to conceptualize the computer and give recommendations for design? How do the three frameworks conceptualize the computer/interaction and give recommendations for design? The WDA analysis within CWA helps identify major usability and UX goals for design based on the work domain and work tasks. This could entail doing ecological interface design by mapping work domain information to a graphical representation through a skills, rules and knowledge taxonomy, with the aim to enable users to interact with the information in these three ways. For example, with this approach human-computer interfaces have been design for use in the petrochemical industry [49].

In HWID, relations between work (HW) and interaction design (ID) happens through and is expressed in design artefacts. HWID is thus to be thought of as a design research approach, where the designed IT artefacts are part of the resulting new knowledge production. For example, a mobile interface for illiterate users with weak motor skills may be produced as part of a HWID analysis that also provides insights into work domains, interaction designs, and socio-cultural contexts [46].

TF's interpretive flexibility of HCI designs lead to recommendations about tangible artifacts and knowledge and methods for technical and knowledge communication. For example, Khoo et al. [47] identified 'findability' as an important issue for one group of librarians, and furthermore, that not only did resource retrieval depend on 'metadata', but so did the wider perceptions of the usability of digital libraries in general. In the social constructivist spirit of TF, they argue that the findings are important not only to the design of the digital library and its evaluation, but also to the design of the roles of users and designers in such evaluation.

While the CWA conceptualize the computer/interaction with a skills, rules and knowledge taxonomy and give recommendations for design that are domain specific, TF co-constructs user roles and computer/interaction, and HWID take a design research approach in which the designed computer/interaction is part of the new produced HCI knowledge.

How should context be taken into account? How should context be taken into account? A forceful argument is that changes in economic paradigms enforce new contexts for HCI: from the usability of industrial economy, the user experience of the experience economy, the social media and open platforms of the knowledge economy, and most recently, the ethical issues and emphatic livings labs of the transformation economy.

In CWA, context is understood and modelled not as a separate entity, but at different levels, including physical description of a work domain. More recent approaches also 
include designing for intentional systems which needs to include analysis of how the environment is constrained by actors' intentions, values, and priorities of practice [24]. Thus, even in analysis of wider societal contexts, CWA remains sensitive to local, contextual details, which cannot be anticipated, by adopting a constraint-based approach.

What is the relevant HWID context is determined by the temporal unfolding of relations between individual interaction designs and organizational work issues and processes. Today, in the current trend of globalization of HCI, it is obvious that the diversity in national cultural contexts shape the ways that HCI designs emerge between work analysis and interaction design. For example, a study of supporting human collaborative works by monitoring everyday conversations made sense when the Japanese context with an increasing elderly population was explained; a study of designing a health-care worker-centred system for a chronic mental care hospital made sense when the Brazilian context of less economic resources was explained, etc. So in HWID, context matters.

In $\mathrm{TF}$, the context is per definition an organizational context, and not the wider societal or technological context. For example, Khoo et al (2012) argue that the usability evaluator carries out her analysis in the "context of her HCI technological frame" [47].

Context in CWA is taken into account as 'environment' and analysed by looking at the environmental constraints, while context in TF becomes a social psychological representation, and context in HWID is a relational issue, which has so far often been national cultural contexts.

\subsection{Which of the three approaches to choose for HCI?}

Which of the three approaches to choose for HCI is not only a matter of personal taste, but may be seen as a holistic choice that is related to the wider development of social paradigms. One view of such paradigms is presented by Gardien et al (2014) who sees the economy as going through four stages with the transformative, ethical oriented economy as the most recent. Without finalizing the discussion, it is possible to argue that CWA has it strengths in the industrial and experience economy, $\mathrm{TF}$ in the knowledge economy, and HWID is the most appropriate in today's design for ethical value exchange as it can allow to unfold the ethical dimensions of ST relations, see e.g. [50].

Furthermore, it may be more useful for HCI to take HWID's indifferent position towards the nature of reality, compared to CWAs' marriage to physical reality or TF's basis in social constructivism. HWID also has the advantage of a flexible approach and can accommodate various socio-technical levels of analysis; in contrast CWA has a fixed number of 'levels of physical reality' and TF only focus on social, political and organizational levels. For HCI, the design research approach of HWID appears more natural than the elaborate taxonomies of CWA or the continuous co-construction of users and technology in TF. The final argument for choosing HWID for ST-HCI is that it is the only framework that can handle the diversity of contexts that are important to HCI of today - CWA can handle physical 'environments' and TF social psychological representations, while context in HWID is a relational issue. 


\subsection{Using HWID to do empirical, design-oriented studies}

While it is beyond the scope and space to discuss method implications, as an ST HCI framework HWID should be understood within an interpretative paradigm. It supports bottom up case-specific theory building, supported by HWID framework. The use of grounded theory approaches supported by qualitative analysis software to do open and data tolerant analysis is recommended. At the same time, it is always important to consider the various kind of contexts for the HWID relations. Finally, best practice is to compile data displays that allows cross case comparing and discussion of the shapes of the holistic HWID gestalt.

As with contextual personas example indicated above [48], HWID provides clear handles to inform the design of digital artefacts and services by enabling a socio-technical dissection of design features and decisions in terms of it social and technical origins or implications. It does so by making otherwise invisible relations between the domains of work and design explicit and visible by theorizing them.The HWID framework supports designers in identifying socio-technical issues that are likely to make a functioning system useless once it is deployed in its organizational context of use. Another, more outwardly looking example is the HWID analysis of a mobile app to support fishers in Alibag, India, where it is illustrated how design decisions about visibility of the fish location did not take into account wider implications in the division of labour between large and small boats and the sustainability of fishing practices [50].

\section{Conclusions}

In this paper we have introduced the need for a socio-technical approach to HCI. Three different candidate frameworks have been presented, CWA, HWID TF, and compared in terms of how they address four questions: 1) which interpretation of all the variants of ST is useful for HCI research and practice, which has indeed a specific technical perspective on the interactions with computers? 2) how can HCI researchers take into account several levels of the social while still focusing on the interaction design? 3) how to conceptualize the computer/interaction and give recommendations for design? 4) how should context be taken into account? The analysis of how these questions are addressed by these frameworks highlighted the main following points. CWA is focusing on models of physical realities and is underpinned by organizational psychology and cognitive engineering. Its functionalist perspective makes it ideal as a tool for the future design of interaction in socio-technical systems. TF is focusing on socio-political meaning-making practices around technology and is underpinned by more critical perspectives on the sociology of technology. Its critical perspective makes it ideal to deconstruct technology in terms of the social and political meanings that have shaped it. HWID has the advantages of a relational epistemology which is much needed for doing HCI in the current global economy. This means that HWID both can be used to 'look outward' and make sense of existing socio-technical relations (like TF), and also be used to 'look inward' and inform design of future solutions (like CWA). HWID is therefore being the preferred ST HCI approach. 


\section{References}

1. Bouzekri, E., Canny, A., Martinie, C., Palanque, P., Gris, C.: Using Task Descriptions with Explicit Representation of Allocation of Functions, Authority and Responsibility to Design and Assess Automation. In: Barbara Rita Barricelli, Virpi Roto, Pedro Campos, Torkil Clemmensen, Hannu Kar-vonen, Frederica Gonçalves, Jose Abdelnour-Nocera and Arminda Guerra Lopes (eds.). Springer (2018).

2. Clemmensen, T., Kaptelinin, V., Nardi, B.: Making HCI theory work: an analysis of the use of activity theory in HCI research. Behav. Inf. Technol. 35, 608-627 (2016).

3. Callon, M.: Some elements of a sociology of translation. Polit. Interv. 57-78 (2007).

4. Gal, U., Berente, N.: A social representations perspective on information systems implementation: rethinking the concept of "frames." Inf. Technol. People. 21, 133154 (2008).

5. Cherns, A.B.: Principles of Socio-Technical Design Re-visited. Hum. Relat. 40, 153-162 (1987).

6. Trist, E., Bamforth, K.: Some social and psychological consequences of the Longwall method. Hum. Relat. 4, 3-38 (1951).

7. Pinch, T., Bijker, W.: The social construction of facts and artifacts. In: The social Construction of Technological Systems. pp. 17-50. MIT Press, Cambridge, MA (1987).

8. Woolgar, S.: Configuring the user: The case of usability trials. In: A Sociology of monsters: essays on Power, Technology and Domination. pp. 58-100. Routledge, London (1991).

9. Mumford, E.: Systems Design: ethical tools for ethical change. Macmillan (1996).

10.Dillon, A.: Group Dynamics Meet Cognition: applying socio-technical concepts in the design of information systems. In: The New SocioTech: Graffiti on the Long Wall. pp. 119-125. Springer Verlag, London (2000).

11. Mackay, H., Carne, C., Beynon-Davies, P., Tudhope, D.: Reconfiguring the user: using Rapid Application Development. Soc. Stud. Sci. 30, 737-757 (2000).

12. Suchman, L.: Plans and Situated Actions. Cambridge University Press, Cambridge (1987)

13.Bijker, W.E.: Of bicycles, bakelites, and bulbs : toward a theory of sociotechnical change. MIT Press, Cambridge, MA (1995).

14. Latour, B.: Reassembling the social: An introduction to actor-network-theory. Oxford university press (2005).

15.Bjørn-Andersen, N., Clemmensen, T.: The Shaping of the Scandinavian Socio-technical IS Research Tradition. Scand. J. Inf. Syst. 29, 79-118 (2017).

16.Kimbell, L.: Rethinking design thinking: Part I. Des. Cult. 3, 285-306 (2011).

17. Gardien, P., Djajadiningrat, T., Hummels, C., Brombacher, A.: Changing your hammer: The implications of paradigmatic innovation for design practice. Int. J. Des. 8, (2014).

18.Guba, E.: The Alternative Paradigm Dialog. In: The Paradigm Dialog. pp. 17-27. Sage, London (1990). 
19.Vicente, K.J.: Cognitive work analysis: Toward safe, productive, and healthy computer-based work. CRC Press (1999).

20.Hirschheim, R., Klein, H.K.: Four paradigms of information systems development. Commun. ACM. 32, 1199-1216 (1989).

21. Abdelnour-Nocera, J., Oussena, S., Burns, C.: Human Work Interaction Design of the Smart University. In: Human Work Interaction Design. Work Analysis and Interaction Design Methods for Pervasive and Smart Workplaces. pp. 127-140. Springer International Publishing (2015).

22.Hajdukiewicz, J., Burns, C.: Strategies for bridging the gap between analysis and design for ecological interface design. In: Proceedings of the Human Factors and Ergonomics Society Annual Meeting. pp. 479-483. SAGE Publications (2004).

23.Burns, C.M., Skraaning, G., Jamieson, G.A., Lau, N., Kwok, J., Welch, R., Andresen, G.: Evaluation of ecological interface design for nuclear process control: situation awareness effects. Hum. Factors J. Hum. Factors Ergon. Soc. 50, 663-679 (2008).

24.Hajdukiewicz, J.R., Burns, C.M., Vicente, K.J., Eggleston, R.G.: Work domain analysis for intentional systems. In: Proceedings of the Human Factors and Ergonomics Society Annual Meeting. pp. 333-337. SAGE Publications (1999).

25.Burns, C.M., Enomoto, Y., Momtahan, K.: A cognitive work analysis of cardiac care nurses performing teletriage. Appl. Cogn. Work Anal. 149-174 (2008).

26.Euerby, A., Burns, C.M.: Improving Social Connection Through a Communities of Practice-Inspired Cognitive Work Analysis Approach. Hum. Factors J. Hum. Factors Ergon. Soc. 0018720813494410 (2013).

27. Rogers, Y., Sharp, H., Preece, J.: Interaction design: beyond human-computer interaction. John Wiley \& Sons (2011).

28. Vicente, K.J.: A history of cognitive engineering research at Risø (1962-1979). In: Proceedings of the Human Factors and Ergonomics Society Annual Meeting. pp. 210-214. SAGE Publications Sage CA: Los Angeles, CA (1997).

29. Clemmensen, T., Orngreen, R., Pejtersen, A.M.: Describing Users in Contexts: Perspectives on Human-Work Interaction Design. In: Workshop Proceedings of Interact. Citeseer (2005).

30. Clemmensen, T.: A Human Work Interaction Design (HWID) Case Study in EGovernment and Public Information Systems. Int. J. Public Inf. Syst. 2011, 105113 (2011).

31. Annett, J., Duncan, K.D.: Task analysis and training design. (1967).

32.Salmon, P., Jenkins, D., Stanton, N., Walker, G.: Hierarchical task analysis vs. cognitive work analysis: comparison of theory, methodology and contribution to system design. Theor. Issues Ergon. Sci. 11, 504-531 (2010).

33. Button, G., Sharrock, W.: Studies of Work and the Workplace in HCI: Concepts and Techniques. Synth. Lect. Hum.-Centered Inform. 2, 1-96 (2009).

34. Abdelnour-Nocera, J., Dunckley, L., Sharp, H.: An approach to the evaluation of usefulness as a social construct using technological frames. Int. J. Hum.-Comput. Interact. 22, 153-172 (2007).

35.Cooper, A., Reimann, R., Cronin, D.: About face 3: the essentials of interaction design. John Wiley \& Sons (2007). 
36.Oh, Y., Do, E.Y.-L., Gross, M.D.: Intelligent critiquing of design sketches. Mak. Pen-Based Interact. Intell. Nat. Ed Randall Davis JL Stahovich T Mill. R Saund E AAAI Press Arlingt. Va. 127-133 (2004).

37. Barricelli, B.R., Valtolina, S., Gadia, D., Marzullo, M., Piazzi, C., Garzulino, A.: Participatory Action Design Research in Archaeological Context. In: Human Work Interaction Design. Work Analysis and Interaction Design Methods for Pervasive and Smart Workplaces. pp. 192-211. Springer (2015).

38. Orlikowski, W., Gash, D.C.: Technological Frames: Making Sense of Information Technology in Organisations. ACM Trans. Inf. Syst. 12, 174-207 (1994).

39.Suchman, L.: Practice-based design of information systems: notes from the hyperdeveloped world. Inf. Soc. 18, 139-144 (2002).

40. Hansen, T.R.: Strings of experiments: looking at the design process as a set of sociotechnical experiments. In: Proceedings of the ninth conference on Participatory design: Expanding boundaries in design. pp. 1-10. ACM Press (2006).

41. Abdelnour-Nocera, J., Dunckley, L.: Sociotechnical research and knowledge communication in community-centred systems design: a technological frames perspective. Int. J. Web Based Communities. 4, 476-490 (2008).

42. Abdelnour-Nocera, J., Camara, S.: Addressing Sociotechnical Gaps in the Design and Deployment of Digital Resources in Rural Kenya. In: Proceedings of the 33rd Annual International Conference on the Design of Communication. pp. 45:1-45:5. ACM, New York, NY, USA (2015).

43. Miller, C.A., Vicente, K.J.: Task “versus” work domain analysis techniques: A comparative analysis. In: Proceedings of the Human Factors and Ergonomics Society Annual Meeting. pp. 328-332. SAGE Publications Sage CA: Los Angeles, CA (1999).

44.Burns, C.: Cognitive work analysis: new dimensions. In: Human Work Interaction Design. Work Analysis and HCI. pp. 1-11. Springer (2013).

45. Gonçalves, F., Campos, P., Clemmensen, T.: Human Work Interaction Design: An Overview. In: Human Work Interaction Design. Work Analysis and Interaction Design Methods for Pervasive and Smart Workplaces. pp. 3-19. Springer (2015).

46.Katre, D., Orngreen, R., Yammiyavar, P., Clemmensen, T.: Human Work Interaction Design: Usability in Social, Cultural and Organizational Contexts: Second IFIP WG 13.6 Conference, HWID 2009, Pune, India, October 7-8, 2009, Revised Selected Papers. Springer (2010).

47.Khoo, M., Kusunoki, D., MacDonald, C.: Finding Problems: When Digital Library Users Act as Usability Evaluators. In: System Science (HICSS), 2012 45th Hawaii International Conference on. pp. 1615-1624. IEEE (2012).

48. Cajander, \AAsa, Larusdottir, M., Eriksson, E., Nauwerck, G.: Contextual personas as a method for understanding digital work environments. In: Human Work Interaction Design. Work Analysis and Interaction Design Methods for Pervasive and Smart Workplaces. pp. 141-152. Springer (2015).

49. Jamieson, G.A., Vicente, K.J.: Ecological interface design for petrochemical applications: supporting operator adaptation, continuous learning, and distributed, collaborative work. Comput. Chem. Eng. 25, 1055-1074 (2001). 
50. Abdelnour-Nocera, J., Nielsen, L., Christensen, L.R., Clemmensen, T.: Socio-technical HCI for Ethical Value Exchange: A Case of Service Design and Innovation 'at the Margins' in Resource Constrained Environments. In: The 16th IFIP TC13 International Conference on Human-Computer Interaction. pp. 254-262. Springer (2017). 